\title{
Relação parasito-hospedeiro entre Psoroptes equi e eqüinos ${ }^{1}$
}

\author{
Michelle G.F. Tancredi ${ }^{2}$, João Luiz H. Faccini ${ }^{3}$, Ian P. Tancredi ${ }^{4}$, Isabella V.F. \\ Martins ${ }^{5}$ e Fabio B. Scott ${ }^{3}$
}

\begin{abstract}
Tancredi M.G.F., Faccini J.L.H., Tancredi I.P., Martins I.V.F. \& Scott F.B. 2005. [The hostrelationship between Psoroptes equi and horses.] Relação parasito-hospedeiro entre Psoroptes equi e eqüinos. Pesquisa Veterinária Brasileira 25(4):207-209. Departamento de Parasitologia Animal, Instituto de Veterinária, Universidade Federal Rural do Rio de Janeiro, Seropédica, RJ 23890-000, Brazil.E-mail: faccini@ufrrj.br

Horses, abandoned by their owners (stray horses) along the main roads in the state of Rio de Janeiro, southeastern Brazil, and brought by the Federal Police to a quarantine station at the Universidade Federal Rural do Rio de Janeiro, were included in the study. A total of 1,121 horses were examined from November 1998 to November 2000. Skin scrapings from $107(9.5 \%)$ horses with signs of psoroptic mange resulted in 37 (34.6\%) positive animals for Psoroptes equi. There was no statistical correlation between prevalence and host age or sex $\left(\chi^{2}, \mathrm{p}>0,05\right)$. P. equi was diagnosed in animals with different hair color. The dorsal region (withers to hip) was the most affected area of the body.
\end{abstract}

INDEX TERMS: Psoroptes equi, Acari, Psoroptidae, mange, horses, Brazil.

RESUMO.- Eqüinos abandonados pelos seus proprietários nas margens das principais rodovias federais que cruzam o Estado do Rio de Janeiro foram incluídos neste estudo. Um total de 1.121 eqüinos apreendidos pela Polícia Rodoviária Federal foi examinado de novembro de 1998 a novembro de 2000. Os 107 $(9,5 \%)$ animais com suspeita clínica de sarna psoróptica foram submetidos a raspados cutâneos superficiais e nestes a espécie Psoroptes equi foi diagnosticada em 37 (34,6\%). Não houve associação entre a prevalência da infestação e a idade ou sexo do hospedeiro $\left(\chi^{2}, \mathrm{p}>0,05\right)$. Em relação ao tipo de pelagem, P. equi foi diagnosticada em animais com diferentes cores. A região dorsal (cernelha até a anca) foi a mais afetada.

TERMOS DE INDEXAÇÃO: Psoroptes equi, Acari, Psoroptidae, sarna, eqüinos, Brasil

\section{INTRODUÇÃO}

A sarna psoróptica é uma enfermidade que atinge várias espécies de mamíferos herbívoros, tendo como agente etiológico as

\footnotetext{
${ }^{1}$ Recebido em 3 de dezembro de 2004.

Aceito para publicação em 10 de maio de 2005.

${ }^{2}$ Aluna de Pós-Graduação em Ciências Veterinárias, Universidade Federal Rural do Rio de Janeiro (UFRRJ), Seropédica, RJ 23890-000.

3 Depto Parasitologia Animal, Instituto de Veterinária, UFRRJ. Bolsista do CNPq. "Autor para correspondência. E-mail: faccini@ufrrj.br

${ }^{4}$ SEAAPI / RJ, Alameda São Boaventura, 770, Fonseca, Niterói, RJ.

${ }^{5}$ Depto Zootecnia e Economia Rural,Centro de Ciências Agrárias, UFES, Alto Universitário, Cx. Postal 16, Bairro Guararema, Alegre, ES 29500-000.
}

espécies do gênero Psoroptes. Os principais artigos publicados sobre sarna psoróptica dos animais domésticos abordam o tema em relação aos caprinos, coelhos, bovinos e ovinos (Bates 1999, Losson et al. 1999, van den Broek \& Huntley 2003). Debilidade, queda na produção e até mesmo a morte dos hospedeiros são as principais consequiências do parasitismo nestas espécies.

Em contrapartida, dados relativos às infestações por Psoroptes sp em equiinos restringem-se a simples citações da presença da espécie entre outros parasitos de equiinos, em listas ou livros texto. Kettle (1995) cita a ocorrência desta parasitose somente na Inglaterra e África do Sul, enquanto Urquhart et al. (1988) ressaltam que o parasitismo em equiinos por espécies do gênero Psoroptes, nos Estados Unidos da América do Norte e Austrália, restringe-se ao conduto auditivo. Segundo estes autores, esta modalidade de parasitismo é comum na Austrália. No Brasil, os artigos publicados sobre o tema referem-se apenas a citações de ocorrência das infestações por $P$. equi em eqüinos nos Estados do Rio de Janeiro, Minas Gerais, Mato Grosso do Sul, São Paulo, Paraná, Santa Catarina e Rio Grande do Sul (Guimarães et al. 2001), embora a enfermidade seja conhecida há pelo menos sete décadas (Pinto 1938).

A despeito da quantidade de artigos publicados sobre a validade das várias espécies de Psoroptes (Zhaler et al. 2000), ainda pairam dúvidas sobre a etiologia da sarna psoróptica dos eqüinos. Para efeito deste artigo, seguiremos a proposta de Zhaler et al. (2000), considerando ser Psoroptes equi a espécie que parasita os equiinos.

Dados sobre a relação parasito-hospedeiro entre $P$. equi e eqüinos no Brasil ainda não constam da literatura. 


\section{MATERIAL E MÉTODOS}

Foram examinados eqüinos utilizados para o trabalho atrelados a carroças de remoção de entulhos e/ou transporte de material de pequena monta como material de construção, mobiliário residencial, etc. Os animais eram de idade e pelagem variadas, ambos os sexos e sem raça definida. Embora possuam dono, os mesmos não são registrados, impossibilitando deste modo, uma avaliação adequada do estado de higidez dos mesmos.

Os animais foram apreendidos pela Polícia Rodoviária Federal vagando à beira das estradas BR 040, BR 101, BR 116, BR 393, BR 493 e BR 494 nos trechos que as mesmas cortam o Estado do Rio de Janeiro (www.dner.gov.br) e trazidos para o Curral de Apreensão do Convênio Polícia Rodoviária Federal / UFRRJ.

No período de novembro de 1998 a novembro de 2000 foram examinados 1.121 eqüinos. Durante o exame clínico, animais com sinais e/ou lesões sugestivas da presença de Psoroptes sp tais como alopecia, prurido, presença de crostas ou descamação ou ainda a combinação de um ou mais sinais juntamente com escoriações, foram separados dos demais e submetidos a raspado superficial de pele. Este é o procedimento padrão nos casos suspeitos de sarna psorótica (O’Brien 1999). Segundo o referido autor, o diagnóstico pode ser feito pela observação clínica e o histórico dos animais suspeitos, sendo então confirmado pela presença dos ácaros em raspados cutâneos.

O material coletado foi depositado em placa de Petri previamente identificada, e transportado ao Departamento de Parasitologia Animal, Convênio "Projeto Sanidade Animal Embrapa/UFRRJ".

Fichas individuais foram elaboradas contendo informações sobre a idade, avaliada pela cronologia dentária segundo Costa (1997), o sexo e a pelagem dos hospedeiros e a descrição sucinta do local das lesões, segundo as áreas anatômicas descritas em Costa (1997). Um desenho esquemático de um eqüino em papel milimetrado serviu de modelo para a avaliação visual do local e da extensão das lesões.

No laboratório, os raspados foram examinados em microscópio estereoscópico para a identificação dos espécimes de Psoroptes sp.

Utilizou-se o teste do Qui-quadrado (Zar 1996) para avaliar uma possível associação entre a idade e o sexo do hospedeiro com a prevalência da infestação. Em relação à idade, os animais foram agrupados em 3 classes de acordo com Costa (1997): potros (animais até 5 anos), adultos (entre 6 e 12 anos) e senis (animais com mais de 12 anos).

\section{RESULTADOS}

Do total de 1.121 animais examinados durante os dois anos de estudo, o exame clínico revelou 107 (9,5\%) eqüinos suspeitos de sarna psoróptica. Destes, 37 (34,6\%) animais estavam positivos para Psoroptes equi.

A idade não foi um fator limitante para a infestação por $P$. equi, uma vez que foram observados animais infestados dos 1,5

Quadro 1. Prevalência da sarna psoróptica em eqüinos apreendidos em estradas federais do Estado do Rio de Janeiro, durante o período de novembro de 1998 a novembro de $\mathbf{2 0 0 0}$, de acordo com a idade

\begin{tabular}{cccc}
\hline Idade (anos) & Animais suspeitos & Animais positivos & Prevalência (\%) \\
\hline Potro $(0-5)$ & 34 & 11 & 32,4 \\
Adulto $(6-12)$ & 59 & 18 & 30,5 \\
Senil $(\geq 13)$ & 14 & 8 & 57,1 \\
Total & 107 & 37 & 34,6
\end{tabular}

Quadro 2. Prevalência da sarna psoróptica em eqüinos apreendidos em estradas federais do Estado do Rio de Janeiro, durante o período de novembro de 1998 a novembro de 2000, de acordo com o sexo

\begin{tabular}{cccc}
\hline Sexo & Animais suspeitos & Animais positivos & Prevalência (\%) \\
\hline Fêmeas & 49 & 15 & 30,6 \\
Machos & 58 & 22 & 37,9 \\
Total & 107 & 37 & 34,6
\end{tabular}

Quadro 3. Prevalência da sarna psoróptica em eqüinos apreendidos em estradas federais do Estado do Rio de Janeiro, durante o período de novembro de 1998 a novembro de $\mathbf{2 0 0 0}$, de acordo com a pelagem

\begin{tabular}{cccc}
\hline Pelagem & Animais suspeitos & Animais positivos & Prevalência (\%) \\
\hline Preta & 2 & 0 & 0,0 \\
Castanha & 33 & 12 & 36,4 \\
Alazã & 13 & 2 & 15,4 \\
Pampa & 11 & 6 & 54,5 \\
Baia & 10 & 4 & 40,0 \\
Tordilha & 29 & 9 & 31,0 \\
Rosilha & 5 & 2 & 40,0 \\
Branca & 4 & 2 & 50,0 \\
Total & 107 & 37 & 34,6
\end{tabular}

até 20 anos (Quadro 1). A prevalência da infestação nos animais suspeitos foi mais alta nos animais senis, embora o teste do Quiquadrado não tenha revelado associação significativa $(p>0,05)$ entre idade e prevalência. No entanto, entre os animais positivos, os adultos foram 1,6 vez mais infestados que os jovens e 2,3 vezes mais infestados que os senis.

O sexo do hospedeiro (Quadro 2) também não foi um fator limitante. O parasitismo foi diagnosticado tanto nos machos como nas fêmeas. A prevalência da infestação nos animais suspeitos foi mais alta nos machos, embora o teste do Qui-quadrado não tenha revelado associação significativa $(p>0,05)$ entre sexo e prevalência. No entanto, entre os animais positivos, os machos estavam 1,5 vez mais parasitados.

Foram observados equiinos de oito pelagens distintas (Quadro 3). Excetuando-se os dois animais suspeitos de pelagem ne-

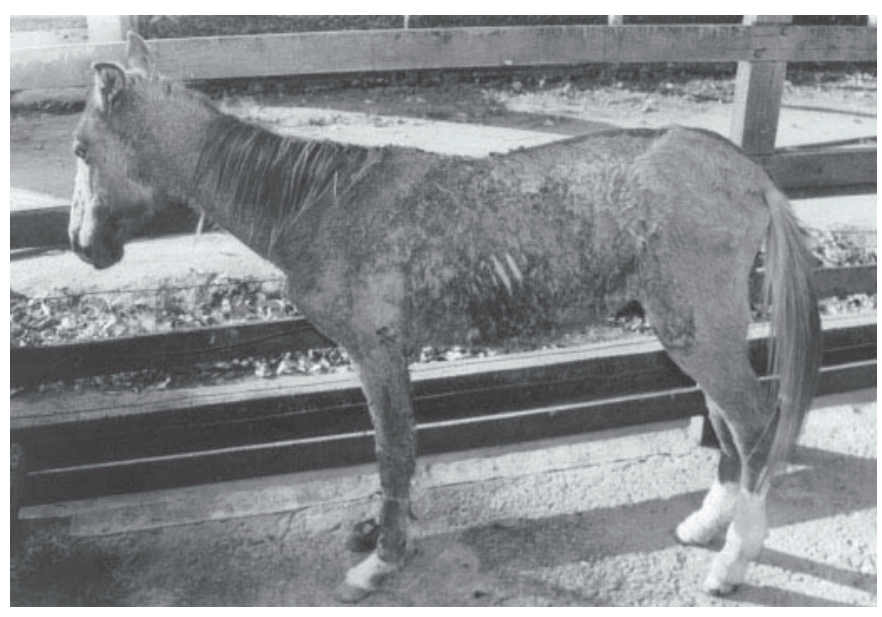

Fig.1. Potro com hipotricose bilateral generalizada e severa, presença de crostas e feridas abertas em extensa área corporal. 
gra, os demais grupos apresentaram animais parasitados com prevalência variando de 15,4 a 54,5\%. Animais de pelagem pampa foram mais freqüentemente acometidos pela sarna psoróptica.

A extensão dos sinais e/ou lesões associadas com a presença de P. equi variou entre os animais positivos, desde hipotricose e presença de crostas em uma região restrita como cernelha, pescoço e espádua até hipotricose, alopecia, presença de exudato seroso a sanguinolento formando crostas, hiperpigmentação e descamação de extensas áreas lesionadas (Fig.1). Em relação às regiões do corpo agrupadas segundo Costa (1997), a região dorsal (da cernelha até as ancas) foi a mais acometida pelo parasitismo, seguida da região média ventral (espádua, peito, ventre, costado, coxa, nádega) e da região do pescoço (crineira e tábua do pescoço). O corpo do animal, então, foi o local de eleição para o parasitismo; os membros e a cabeça, embora também estivessem parasitados, parecem ser locais menos favoráveis para a colonização dos ácaros.

A bilateralidade na distribuição das lesões foi mais freqüientemente observada do que as lesões unilaterais, quer sejam no antímero direito ou no antímero esquerdo.

\section{DISCUSSÃO}

Em seu artigo de revisão, van den Broek \& Huntley (2003), citando os resultados de uma tese de doutorado desenvolvida na Irlanda, mencionam que o autor não evidenciou nenhuma predisposição de raça, sexo ou idade de ovino para a infestação por Psoroptes ovis em ovinos domésticos. Esta situação discorda, até certo ponto, dos resultados publicados por Sarginson et al. (1995), os quais observaram que a sarna de ovinos domésticos pode afetar animais de todas as idades, sendo, no entanto, mas severa em carneiros jovens.

Em relação aos poucos artigos publicados sobre sarna psoróptica de ruminantes selvagens, nota-se também alguma controvérsia. Ao pesquisar a sarna nos ovinos selvagens (Ovis canadensis) no Estado do Arizona (EUA), Welsh \& Bunch (1983) observaram que a infestação foi mais severa nos machos. Segundo Mazet et al. (1992), animais adultos (mais de 2 anos) da espécie Ovis canadensis de origem canadense foram 2,7 vezes mais soropositivos do que animais jovens, porém os autores não encontraram associação significativa entre sexo do hospedeiro e prevalência da infestação.

A despeito das controvérsias que ainda persistem, os dados obtidos em ruminantes somados aos deste artigo sugerem que os fatores relacionados exclusivamente ao hospedeiro não interferem na prevalência da infestação, indicando que a sarna psoróptica pode acometer tanto ruminantes como eqüinos de todas as idades, ambos os sexos e pelagem.

Van den Broek \& Huntley ( 2003) afirmam que P. ovis é uma espécie de ácaro parasito não invasivo, vivendo sobre a pele e se alimentando na epiderme, ingerindo fluidos e exudatos celula- res. Este comportamento alimentar, além de provocar reações alérgicas, favoreceria a colonização da epiderme por bactérias oportunistas. Nas condições em que este estudo foi realizado, pode-se concluir que as alterações macroscópicas associadas ao parasitismo por $P$. equi em eqüinos são compatíveis com as alterações descritas em outras espécies de hospedeiros.

Em relação às regiões do corpo dos equiinos, os resultados indicam que os parasitos se desenvolvem, preferencialmente, na parte dorsal dos animais e bilateralmente.

Destaca-se que segundo van den Broek \& Huntley (2003) uma única fêmea ovígera é suficiente para promover a transmissão da parasitose entre ovinos e que os ácaros coletados em ovinos permanecem infestantes por um período de até 16 dias fora do hospedeiro.

Considerando os resultados obtidos e os textos de outros autores, a probabilidade destes animais serem uma fonte de transmissão desta parasitose para os rebanhos equïnos de maior valor comercial não pode ser descartada.

\section{REFERÊNCIAS}

Bates P.G. 1999. Inter- and intra-specific variation within the genus Psoroptes (Acari: Psoroptidae). Vet. Parasitol. 83(3-4):201-217.

Costa L.A.P. 1997. Manual de Hipologia. Coleção Marechal Trompswsky. Vol. 9. Biblioteca do Exército Editora, Rio de Janeiro. 249p.

Guimarães J.H., Tucci E.C. \& Barros-Battesti D.M. 2001. Ectoparasitos de Importância Veterinária. Editora Plêiade, São Paulo. 218p.

Kettle D.S. 1995. Medical and Veterinary Entomology. 2nd ed. CAB International, Wallingford, UK. 725p.

Losson B.J., Lonneaux J.F. \& Lekimme M.1999.The pathology of Psoroptes ovis infestion in cattle with a special emphasis on breed difference. Vet. Parasitol. 83(3-4): 219-229.

Mazet J.A.K., Boyce W.M., Mellies J., Gardner I.A., Clark R.K. \& Jessup D.A. 1992. Exposure to Psoroptes sp mites is common among bighorn sheep (Ovis canadensis) population in California. J. Wildl. Dis. 28 (4):542-547.

O'Brien D.J. 1999. Treatment of psoroptic mange with reference to epidemiology and history. Vet. Parasitol. 83(3-4):177-185.

Pinto C. 1938. Zôo-parasitos de Interesse Médico e Veterinário. Pimenta de Melo \& Cia., Rio de Janeiro. 376p.

Sarginson N.D., Scott P.R., Penny C.D. \& Pirie R.S. 1995.Effect of an outbreak of sheep scab (Psoroptes ovis) infestation during mid-pregnancy on ewe body condition and lamb birthweight. Vet. Rec.136(9):287-289.

Urquhart G.M., Armour J., Duncan J.L., Dunn A.M., \& Jennings F.W. 1988. Veterinary Parasitology. Longman Scientific \& Technical, Essex, UK. 286p.

Van den Broek A.H. \& Huntley J.F. 2003. Sheep scab: the disease, pathogenesis and control. J. Comp. Path. 128(2-3):79-91.

Welsh G.W. \& Bunch T.D. 1983. Psoroptic scabies in desert bighorn sheep (Ovis canadensis nelsoni) from Northwestern Arizona. J. Wildl. Dis.19(4): 42-344.

Zahler M., Hendrix W.M.L., Essig A., Rinder H. \& Gother R. 2000. Species of the genus Psoroptes (Acari: Psoroptidae): a taxonomic consideration. Exp. Appl. Acarol. 24(3):213-225.

Zar J. H.1996. Biostatistical Analysis. 3rd ed. Prentice-Hall Inc., New Jersey, USA. 662p. 